\title{
Neem oil (Azadirachta indica A. Juss) affects the ultrastructure of the midgut muscle of Ceraeochrysa claveri (Navás, 1911) (Neuroptera: Chrysopidae)
}

\author{
Elton Luiz Scudeler ${ }^{\mathrm{a}, *}$, Ana Silvia Gimenes Garcia ${ }^{\mathrm{a}}$, Patricia Fernanda Felipe Pinheiro ${ }^{\mathrm{b}}$, \\ Daniela Carvalho dos Santos ${ }^{\text {a }}$ \\ a Laboratory of Insects, Department of Morphology, Institute of Biosciences of Botucatu, UNESP - São Paulo State University, Botucatu, SP, Brazil \\ ${ }^{\mathrm{b}}$ Department of Anatomy, Institute of Biosciences of Botucatu, UNESP - São Paulo State University, Botucatu, SP, Brazil
}

\section{A R T I C L E I N F O}

\section{Article history:}

Received 27 September 2016

Received in revised form

29 November 2016

Accepted 29 November 2016

\section{Keywords:}

Biopesticide

Cytotoxicity

Green lacewing

Midgut

Ultrastructure

\begin{abstract}
A B S T R A C T
Cytomorphological changes, by means of ultrastructural analyses, have been used to determine the effects of the biopesticide neem oil on the muscle fibers of the midgut of the predator Ceraeochrysa claveri. Insects, throughout the larval period, were fed eggs of Diatraea saccharalis treated with neem oil at a concentration of $0.5 \%, 1 \%$ or $2 \%$. In the adult stage, the midgut was collected from female insects at two stages of adulthood (newly emerged and at the start of oviposition) and processed for ultrastructural analyses. In the newly emerged insects obtained from neem oil treatments, muscle fibers showed a reduction of myofilaments as well as swollen mitochondria and an accumulation of membranous structures. Muscular fibers responded to those cellular injuries with the initiation of detoxification mechanisms, in which acid phosphatase activity was observed in large vesicles located at the periphery of the muscle fiber. At the start of oviposition in the neem oil treated insects, muscle fibers exhibited signs of degeneration, containing vacant areas in which contractile myofilaments were reduced or completely absent, and an accumulation of myelin structures, a dilatation of cisternae of sarcoplasmic reticulum, and mitochondrial swelling and cristolysis were observed. Enzymatic activity for acid phosphatase was present in large vesicles, indicating that mechanisms of lytic activity during the cell injury were utilized but insufficient for recovery from all the cellular damage. The results indicate that the visceral muscle layer is also the target of action of neem oil, and the cytotoxic effects observed may compromise the function of that organ.
\end{abstract}

(c) 2016 Elsevier GmbH. All rights reserved.

\section{Introduction}

Alternative tools that will help make crop protection more sustainable are currently being evaluated and are providing assistance in integrated pest management (IPM). We emphasize the use of natural products, such as biopesticides and biological control, including predatory insects. Evaluating the integration of non synthetic insecticides and biological control methods is critical to the success of an IPM (Chandler et al., 2011; Cloyd, 2012; El-Wakeil et al., 2013).

A biopesticide is a mass-produced agent manufactured from a living microorganism or a natural product and is sold for the

* Corresponding author. Present address: Laboratório de Insetos, Departamento de Morfologia, Instituto de Biociências de Botucatu, UNESP, Botucatu, SP, CEP: 18618-689, Brazil.

E-mail addresses: escudeler@ibb.unesp.br (E.L. Scudeler), aninhacavassani@yahoo.com.br (A.S.G. Garcia), pinheiro@ibb.unesp.br (P.F.F. Pinheiro), daniela@ibb.unesp.br (D.C.d. Santos). control of plant pests (Bailey et al., 2010; Chandler et al., 2011). Natural products have been identified in plants and can be used as biopesticides. The botanic product that is most widely used is neem oil, an insecticidal chemical extracted from the seeds of the neem tree Azadirachta indica A. Juss (Meliaceae). Azadirachtin is the main active ingredient and is responsible for various actions against insects such as delayed growth and reductions in feeding, fecundity, fertility and repellency (Schmutterer, 1990; Mordue (Luntz) et al., 1998; Mordue (Luntz) and Nisbet, 2000; Morgan, 2009; Okwute, 2012; El-Wakeil et al., 2013).

The evaluation of the side effects that may be associated with the direct or indirect exposure of natural enemies to biopesticides is important for the implementation of the correct tactics in IPM. In spite of being widely used, neem products are being assessed, and their compatibility with natural enemies is being questioned (Medina et al., 2003; Aggarwal and Brar, 2006; Cordeiro et al., 2010; El-Wakeil et al., 2013; Scudeler and Santos, 2013; Scudeler et al., 2013, 2014, 2016a). 
One important method that ecotoxicological studies have been using to investigate sublethal effects on natural enemies is via morphological studies of organs that are in contact way during the exposure to the biopesticides. Morphological and ultrastructural changes in this organ can provide information on delayed effects on non-target organisms (Malaspina and Silva-Zacarin, 2006; Scudeler et al., 2016a). Furthermore, this type of analysis contributes to the improved understanding of the mode of action of the biopesticide in the organism.

During exposure via ingestion, the midgut, which is responsible for digestive and absorptive functions, becomes an excellent target organ in ecotoxicological studies (Malaspina and Silva-Zacarin, 2006; Catae et al., 2014; Scudeler et al., 2016a). Cytotoxic effects on epithelial cells of the midgut of the Neotropical green lacewing Ceraeochrysa claveri (Navás, 1911) caused by treatment with neem oil have been described for all stages of development of this predator (Scudeler and Santos, 2013; Scudeler et al., 2014; Scudeler et al., 2016a), but studies directed to the muscle layers that externally surrounds this organ are lacking. A network of circular and longitudinal striated type muscle fibers is responsible for distension and contraction, and provides the structural integrity of the digestive tract and peristaltic activity required for the function of this organ (Park and Shahabuddin, 2000; Secundino et al., 2005; Bernick et al., 2008). Loss of muscle tone and a reduction in gut motility after azadirachtin treatments (Mordue (Luntz) et al., 1985; Mordue (Luntz) and Nisbet, 2000) have been described, but the effects at the cellular level are unknown, especially at the ultrastructural level. This lack of knowledge is present in relation to synthetic pesticides or biopesticides, and little attention has been given to the muscle layer during the cytopathological analysis.

In order to check the occurrence of cell damage and a possible attempt recovery thereof, acid phosphatase is an important enzymatic marker which can act in the detoxification processes and muscle regeneration (Maltz and Oron, 1990; Amirmohammadi et al., 2012; Valizadeh et al., 2013).

With recognition of the importance of this tissue in the maintenance of the physiological functions performed by the midgut, we intend to describe the effect of neem oil intake on muscle cells of the predator $C$. claveri, thus contributing to a better understanding of the mechanism of action of this biopesticide on the midgut.

\section{Materials and methods}

\subsection{Insects}

The $C$. claveri larvae (0-12 h old) used in the bioassays were obtained from a colony of the Laboratory of Insects in the Department of Morphology at the Institute of Biosciences of Botucatu, Botucatu, Brazil. The $C$. claveri colony was reared with a natural diet of eggs of Diatraea saccharalis (Lepidoptera: Crambidae) during the larval stage and with an artificial diet (1:1 honey/yeast solution) in adulthood. The insects were maintained in an environmental chamber (B.O.D. incubator) with controlled climate conditions $\left(25 \pm 1^{\circ} \mathrm{C}\right.$; relative humidity (RH) of $70 \pm 10 \%$ and a light: dark photoperiod of 12L: 12D). Adults of $D$. saccharalis were provided by the CETMA Comércio de Agentes para Controle Biológico, Lençóis Paulista, São Paulo State, Brazil. The D. saccharalis larvae were maintained in the laboratory with an artificial diet under controlled conditions $\left(26 \pm 1{ }^{\circ} \mathrm{C} ; 60 \pm 10 \% \mathrm{RH} ; 14 \mathrm{~L}: 10 \mathrm{D}\right)$.

\subsection{Bioassays}

Newly hatched larvae of $C$. claveri obtained from the stock rearing colony were randomly selected and placed individually in polyethylene boxes $(2 \mathrm{~cm}$ height $\times 6 \mathrm{~cm}$ diameter). These larvae
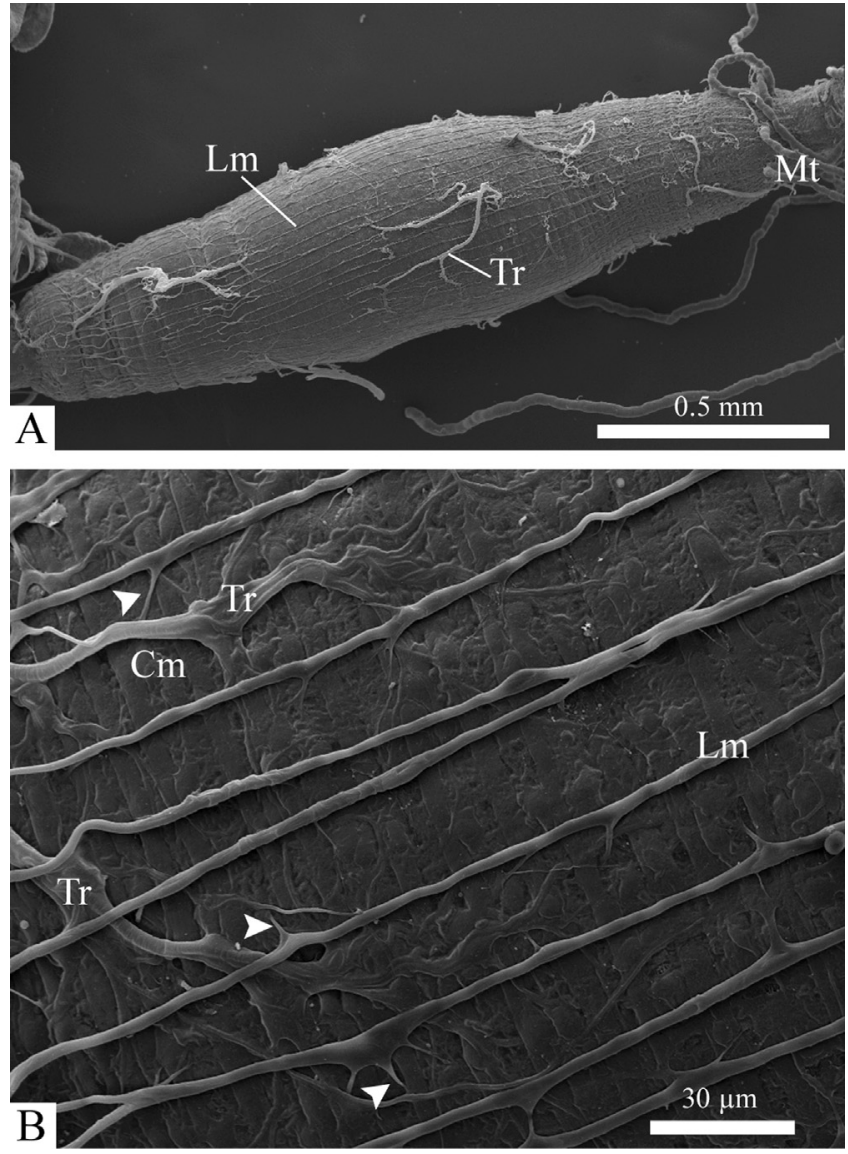

Fig. 1. SEM micrograph of the whole midgut of a newly emerged $C$. claveri adult (control). (A) Longitudinal muscle fibers ( $\mathrm{Lm}$ ) are present, and several tracheoles (Tr) running to midgut. Note also the Malphighian tubules (Mt) starting from the pyloric valve. (B) Muscle fibers are forming a muscle network over the midgut. Longitudinal muscle fibers overlap circular fibers $(\mathrm{Cm})$ and tracheoles that insert this organ. Branching longitudinal muscle (arrowhead).

were exposed to a commercial formulation of neem oil emulsifiable via ingestion (Natuneem ${ }^{\circledR}$, Natural Rural Ind. e Com. de Produtos Orgânicos e Biológicos Ltda, Araraquara-SP, Brazil) (organic product, certified by BCS OKO - Garantie, Doc. Natur - 9009/09.05/7331-BR), pure cold-pressed neem oil extracted from neem seeds containing $1500 \mathrm{ppm}$ of azadirachtin A. Three concentrations $(0.5,1$ and $2 \%)(v / v)$ were evaluated using the recommended label rate for its use in Brazilian agricultural fields and concentrations as previously evaluated for larvae, pupae and adults of C. claveri (Scudeler and Santos, 2013; Scudeler et al., 2014; Scudeler et al., 2016a).

Neem oil solutions were prepared from the commercial formulation and were diluted in distilled water to $0.5 \%(5 \mathrm{~mL} / \mathrm{L}), 1 \%$ $(10 \mathrm{~mL} / \mathrm{L})$, and $2 \%(20 \mathrm{~mL} / \mathrm{L})$; solutions were made daily for use. Fresh egg clusters of $D$. saccharalis were collected and dipped once in neem oil solution for $5 \mathrm{~s}$ and air dried at room temperature for $1 \mathrm{~h}$. For the control group, egg clusters were dipped into distilled water (Scudeler and Santos, 2013).

Larvae were randomly divided into four experimental groups ( $n=30$ per group), and each experimental group comprised five replicates. C. claveri larvae of treated groups $(0.5,1$ and $2 \%)$ were fed with $D$. saccharalis eggs treated with neem oil ad libitum. Likewise, the control group was fed with eggs treated with water ad libitum. This intake of eggs that had or had not been treated with neem oil occurred throughout the larval period until pupation (on average, 13 days). Due to the sensitivity of the neem oil components to ultraviolet light, egg clusters not consumed were replaced every 

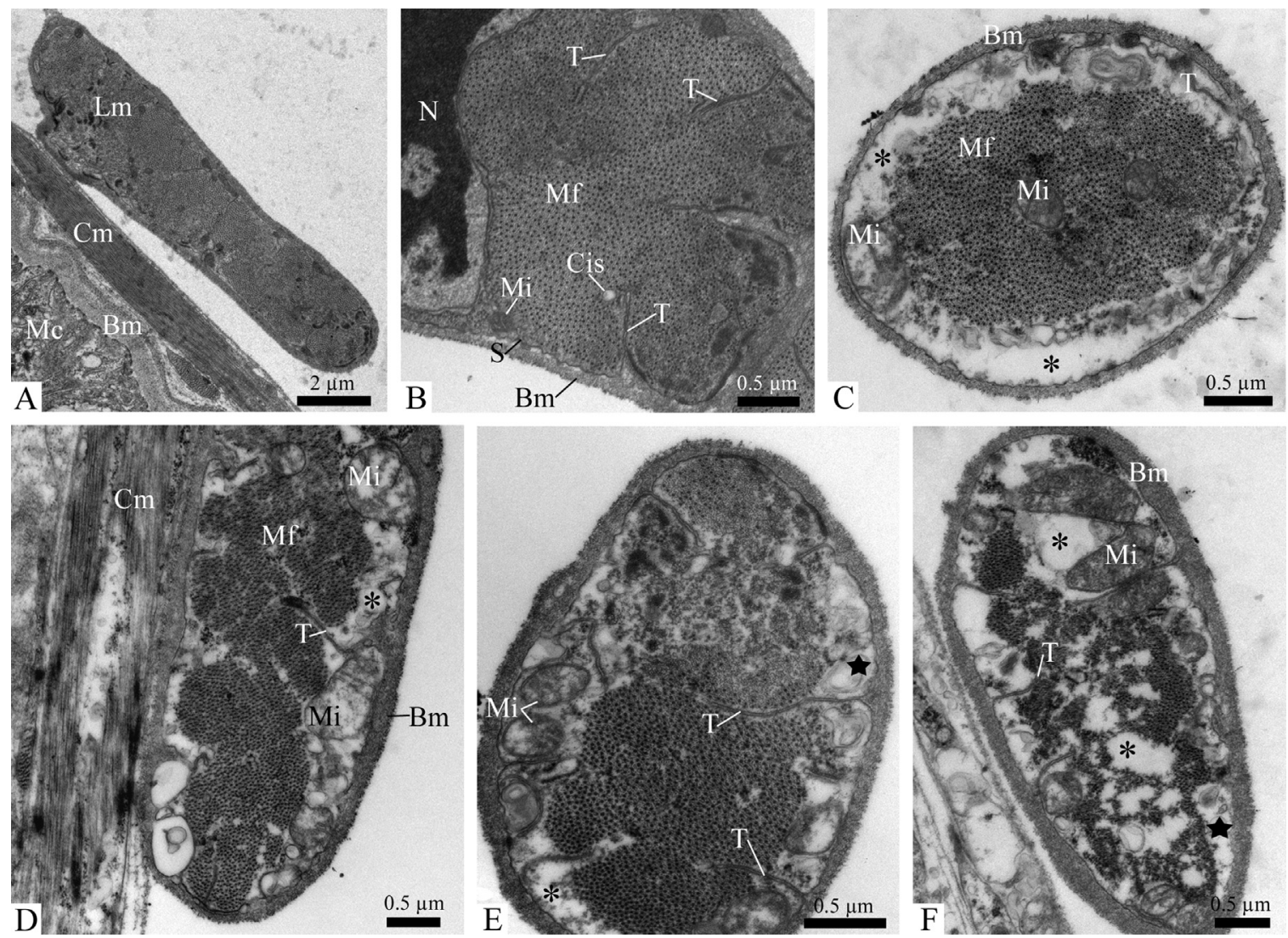

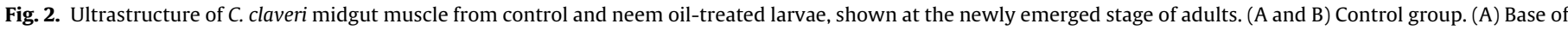

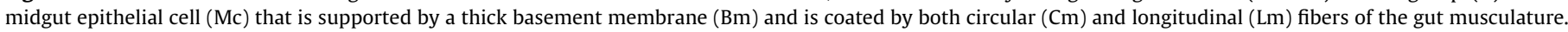

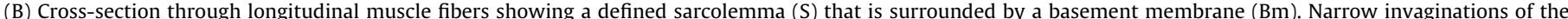

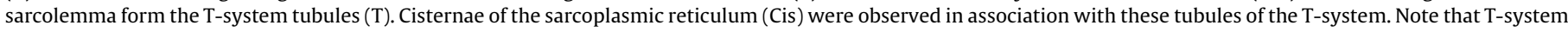

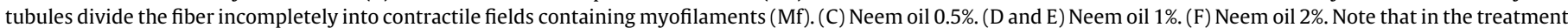

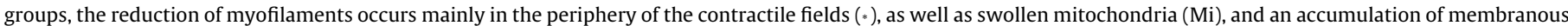
structures (stars) is present. Nucleus $(\mathrm{N})$.

3 days (Scudeler et al., 2016a). According to Schmutterer (1990), the residual effect of neem based products is restricted mostly around five to seven days.

Freshly emerged adults obtained from neem oil-treated larvae $(0-12 \mathrm{~h}$ old $)$ had the sex determined, and one freshly emerged female from the treatment groups was paired with two freshly emerged control males. This trio of insects was kept in a polyethylene box $(9 \mathrm{~cm}$ height $\times 18 \mathrm{~cm}$ diameter $)$ until the start the oviposition (on average 17 days). During this period, the adults were fed with an artificial diet (1:1 honey/yeast solution) and a cotton wick with distilled water every 5 days (Scudeler et al., 2016a). The entire experiment was conducted in the same environmental conditions as described for the insect rearing.

\subsection{Electron microscopy}

Adult females at two ages (0-1 day old and first day of oviposition) obtained from the control and treated groups were quickly cryoanesthetized, and their guts were dissected in saline solution for insects $\left(0.1 \mathrm{M} \mathrm{NaCl}, 0.1 \mathrm{M} \mathrm{Na}_{2} \mathrm{HPO}_{4}\right.$ and $\left.0.1 \mathrm{M} \mathrm{KH}_{2} \mathrm{PO}_{4}\right)$.

\subsubsection{Scanning electron microscopy (SEM)}

Midguts obtained from adult females ( $n=5$ per age/group) were fixed in $2.5 \%$ glutaraldehyde in $0.1 \mathrm{M}$ phosphate buffer ( $\mathrm{pH} 7.3$ ) for $48 \mathrm{~h}$ at room temperature. Thereafter, the samples were washed in distilled water, post-fixed in 1\% osmium tetroxide (Sigma Aldrich, St. Louis, Missouri, USA) diluted in distilled water for $30 \mathrm{~min}$, dehydrated through a graded series of ethanol solutions, critical point-dried using liquid $\mathrm{CO}_{2}$ (Leica CPD 030 critical point dryer) and gold-coated on a Baltec SCD 050 sputter coater. The samples were examined and documented using an FEI Quanta 200 scanning electron microscope (FEI Company, Eindhoven, Netherlands) at the Electron Microscopy Center of the Institute of Biosciences of Botucatu.

\subsubsection{Transmission electron microscopy (TEM)}

Midgut samples from five specimens of adult females of each age and experimental group were fragmented, fixed and processed for transmission electron microscopy as indicated below. All samples were analyzed and photographed in a Tecnai Spirit transmission electron microscope (FEI Company, Eindhoven, Netherlands) at the Electron Microscopy Center of the Institute of Biosciences of Botucatu.

2.3.2.1. Conventional transmission electron microscopy. The transmission electron microscopy procedures were performed in a manner similar to our previous studies on the $C$. claveri midgut (Scudeler and Santos, 2013; Scudeler et al., 2016a). The midgut fragments were fixed in $2.5 \%$ glutaraldehyde and $4 \%$ paraformaldehyde (Merck KGaA, Darmstadt, Germany) solution in $0.1 \mathrm{M}$ phosphate buffer ( $\mathrm{pH} 7.3$ ) for $24 \mathrm{~h}$ at room temperature, and then post-fixed in $1 \%$ osmium tetroxide in the same buffer for $2 \mathrm{~h}$. After washing several times in distilled water, the samples were contrasted with an aqueous solution of $0.5 \%$ uranyl acetate (Electron Microscopy 

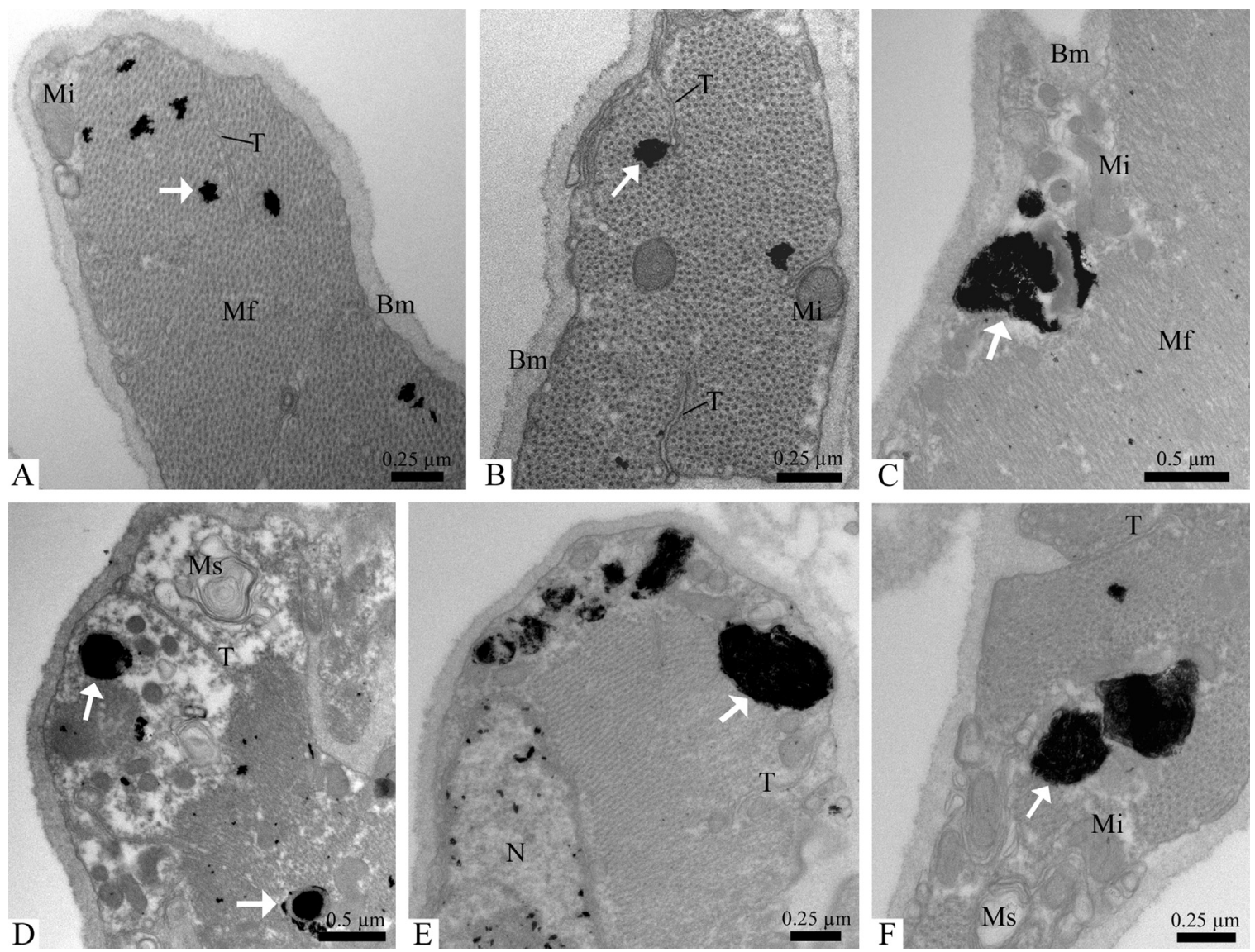

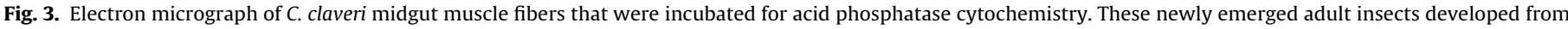

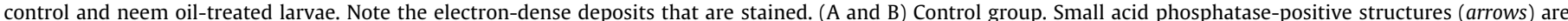

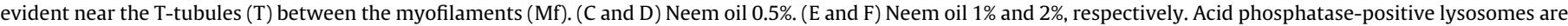

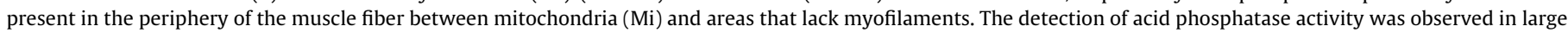
vesicles when compared with the control group. Basement membrane (Bm); nucleus $(\mathrm{N})$; myelin structures (Ms).

Sciences, Hatfield, Pennsylvania, USA) for $2 \mathrm{~h}$ at room temperature, dehydrated in a graded acetone series, and embedded in Araldite resin (Electron Microscopy Sciences, Hatfield, Pennsylvania, USA). Ultra-thin sections were contrasted with uranyl acetate and lead citrate (Electron Microscopy Sciences, Hatfield, Pennsylvania, USA) and then analyzed in a Tecnai Spirit transmission electron microscope.

2.3.2.2. Ultrastructural cytochemical analysis. The activity of acid phosphatase, a lysosomal marker with a possible effect on cellular repair, was examined in the tissues in a manner identical to that used by Scudeler et al. (2016a) in previous experiments on midgut epithelium of $C$. claveri. Midgut fragments were fixed in $2.5 \%$ glutaraldehyde and $2 \%$ paraformaldehyde solution in $0.1 \mathrm{M}$ sodium cacodylate buffer ( $\mathrm{pH} 7.2$ ) with 5\% sucrose for $20 \mathrm{~min}$, washed several times in sodium cacodylate buffer with $5 \%$ of sucrose and washed twice in $0.05 \mathrm{M}$ acetate buffer ( $\mathrm{pH} 5.0$ ) with $5 \%$ of sucrose. Afterwards, the tissues were incubated in a solution of cytidine5'-monophosphate (Sigma Aldrich, St. Louis, Missouri, USA) and 1\% lead nitrate (Electron Microscopy Sciences, Hatfield, Pennsylvania, USA) in acetate buffer ( $\mathrm{pH} \mathrm{5.0)}$ ) for $1 \mathrm{~h}$ at $37^{\circ} \mathrm{C}$ (Pino et al., 1981 ). Post-fixation was performed in $2.5 \%$ glutaraldehyde and $2 \%$ paraformaldehyde solution in $0.1 \mathrm{M}$ sodium cacodylate buffer $(\mathrm{pH}$ 7.2 ) with $5 \%$ sucrose for $45 \mathrm{~min}$ and with $1 \%$ osmium tetroxide in cacodylate buffer for $1 \mathrm{~h}$. Finally, the samples were dehydrated and embedded following the procedures for conventional analysis. Unstained ultra-thin sections were used for cytochemical analysis.
The positive reaction in the cytochemical analysis is observed in the sections as electron-dense regions.

\section{Results}

The outer surface of the adult of $C$. claveri midgut is organized as a grid-like network composed of circular and longitudinal fibers. The longitudinal fibers were always positioned over the circular ones, and this orientation of the fibers was uniform throughout the midgut. The tracheoles that insert into this organ and the small branches of longitudinal fibers that result in the interconnection and fixation of fibers across much of the length of the midgut can be observed in SEM images (Fig. 1A and B).

Ultrastructural analysis of the basal region of the pseudostratified epithelium of freshly emerged $C$. claveri adults revealed that midgut epithelial cells rest on a basement membrane and are wrapped by muscle fiber bundles that form an internal circular tunic and another external longitudinal tunic (Fig. 2A). In the control group, muscle fibers showed a well-defined sarcolemma that was surrounded by a basement membrane. Narrow invaginations of the sarcolemma form the T-system tubules and sarcoplasmic reticulum cisternae were observed in association with these tubules. The nucleus and electron-dense mitochondria were observed in the periphery of the incomplete contractile fields filled by myofilaments that had been formed by invaginations of the T-tubules (Fig. 2B).

In the three neem oil treatment groups, we noticed severe ultrastructural changes. Muscle fibers showed a reduction of 

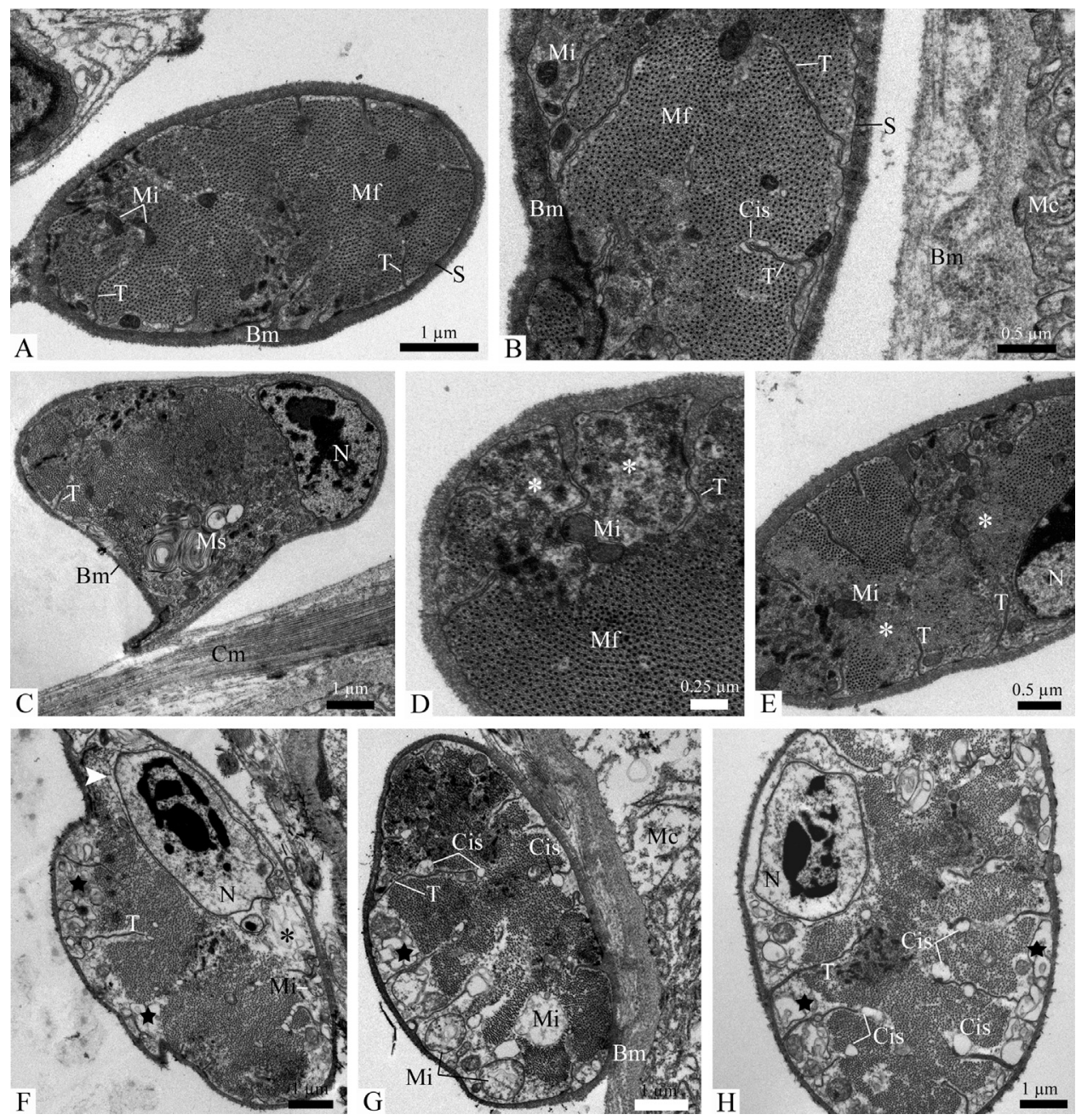

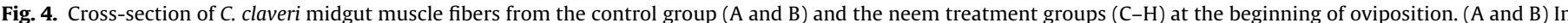

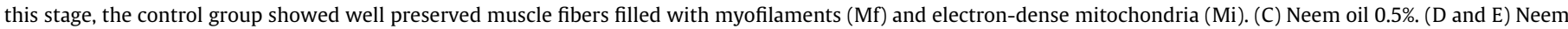

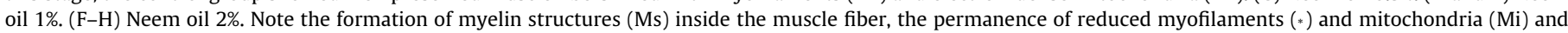

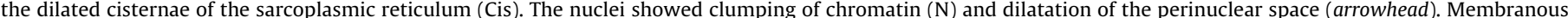
structures (stars) accumulated in the periphery of the fiber. Basement membrane (Bm); midgut epithelial cell (Mc); sarcolemma (S); T-system tubules (T).

myofilaments mainly in the periphery of the contractile fields, as well as swollen mitochondria and an accumulation of membranous structures near the sarcolemma (Fig. 2C-F).

The midgut muscle fibers, which were incubated for acid phosphatase cytochemistry, exhibited small acid phosphatase-positive structures near the T-tubules between the myofilaments in freshly emerged adults in the control group (Fig. $3 \mathrm{~A}$ and $\mathrm{B}$ ). In the neem treatment groups, acid phosphatase activity was observed in large vesicles present in the periphery of the muscle fiber between mitochondria and areas that lacked myofilaments (Fig. 3C-F).

At the start of oviposition, insects in the control group exhibited preserved muscle fibers with myofilaments, electron-dense mitochondria near the T-tubules and a sarcoplasmic reticulum associated with tubules (Fig. 4A and B). In the insects exposed to neem oil during the larval stage, muscle fibers still exhibited some degree of degeneration. Some muscle fibers contained vacant areas in which the contractile myofilaments were reduced or completely absent, and an accumulation of myelin structures, a dilatation of the cisternae of the sarcoplasmic reticulum and mitochondrial swelling and cristolysis were observed. The nuclei showed clumping of chromatin and a dilatation of perinuclear space. Membranous structures had accumulated in the periphery of the muscle fibers (Fig. 4C-H).
The acid phosphatase activity was localized in the control group to small areas present on the basement membrane and small vesicles in the periphery of the muscle fiber and near the T-tubules at the beginning of oviposition (Fig. 5A and B). Nonetheless, strong enzymatic activity was present in large vesicles localized in the periphery of the muscle fibers in insects that had received the neem treatments (Fig. 5C-F).

\section{Discussion}

We examined the midgut muscle organization and also provided an ultrastructural explanation of its morphology and the occurrence of ultrastructural changes caused by the ingestion of neem oil to better elucidate the mode of action of this biopesticide on this organ.

In $C$. claveri, the midgut visceral muscle presented with a similar organization as in other species of insects and was formed by a well-organized network of circular and longitudinal muscle fibers. The maintenance of visceral muscle function and integrity is important because visceral muscles provide peristaltic movements for the digestion and assimilation of ingested food (Park and Shahabuddin, 2000; Secundino et al., 2005; Bernick et al., 2007), and play an important role in homeostasis, physiology and regeneration 

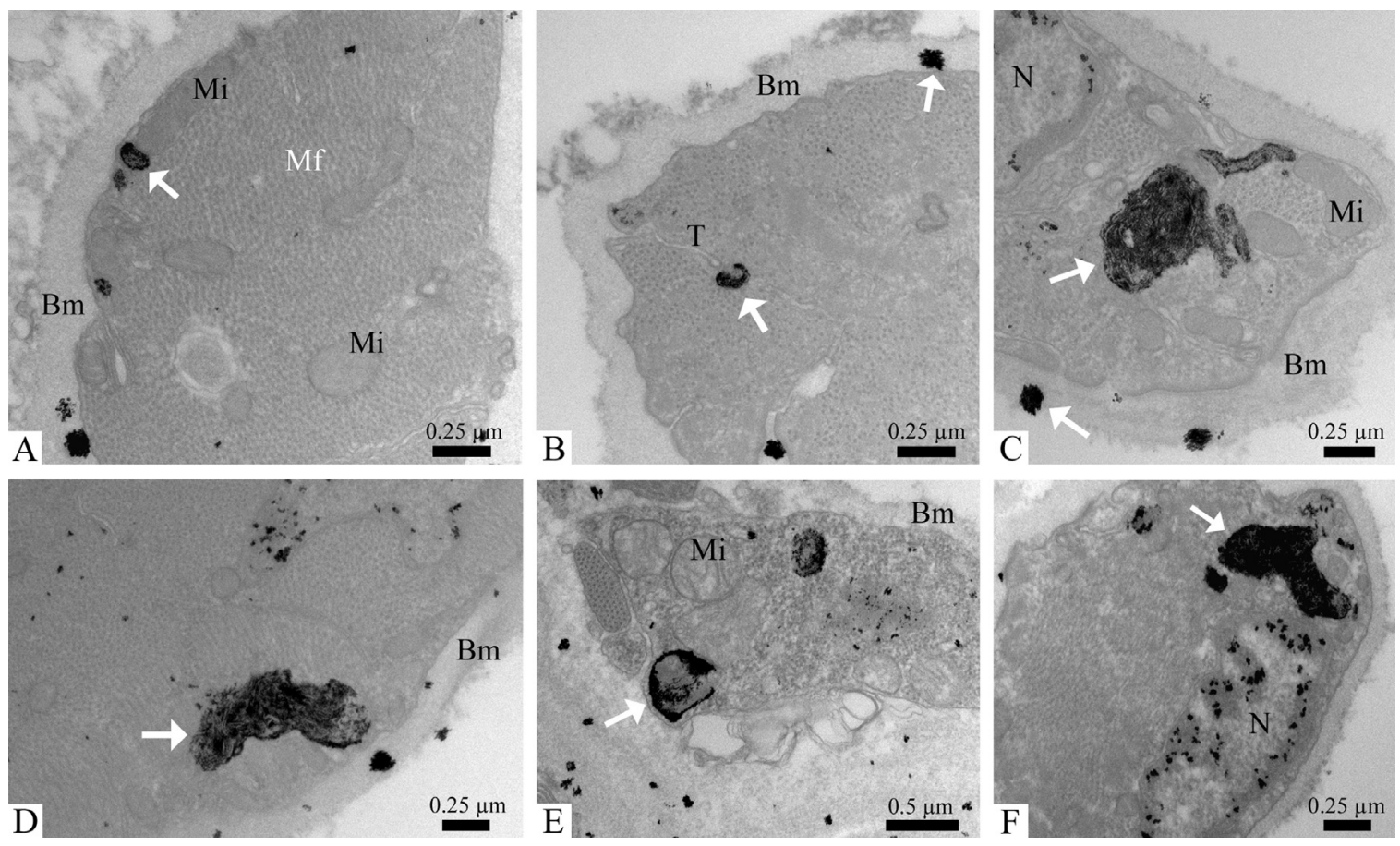

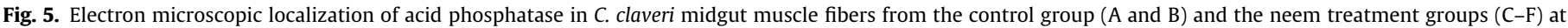

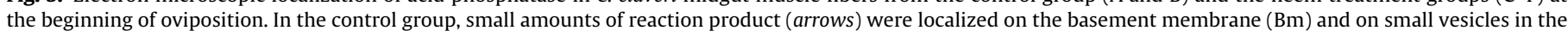

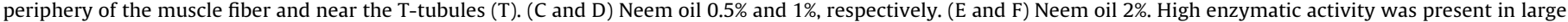
vesicles localized in the periphery of the muscle fiber. Nucleus (N); mitochondria (Mi); myofilaments (Mf).

in local tissue. In addition, the midgut muscles are an important component that can control the intestinal stem cell niche (Xu et al., 2011; Kux and Pitsouli, 2014).

Studies such as those conducted by Schaefer et al. (1967) and Bernick et al. (2007, 2008) included ultrastructural analyses that were performed to assist in the characterization of the muscle fibers, primarily to understand the organization of these components in these cells. The analysis of these components of the midgut is lacking, and many studies only describe the epithelium structure, neglecting this important element of the digestive system. Many articles have approached briefly changes caused by exposure to different types of insecticides in the midgut which impair the visceral muscle (Nasiruddin and Mordue (Luntz), 1993; Ling and Zhang, 2011; Ruiu et al., 2012; Almeida et al., 2014; Gutiérrez et al., 2016), consequently little information has been presented to readers.

Exposure to azadirachtin, the predominant component of neem oil, leads to the loss of muscle tone (Mordue (Luntz) and Nisbet, 2000), muscles become swollen and disrupted (Nasiruddin and Mordue (Luntz), 1993; Mordue (Luntz) and Blackwell, 1993) and a reduction in gut motility occurs after azadirachtin treatment(Mordue (Luntz) et al., 1985). Scudeler et al. (2016b) described the difficulty that some female $C$. claveri had in the elimination of the meconium from the alimentary canal, resulting in a shorter survival of these insects (only 53\% for group treated with $2 \%$ ) after neem oil ingestion in the larval instars. Changes in gut motility may affect the ability to eliminate meconium. A similar effect was observed in Bombyx mori. Munhoz et al. (2013) described larvae that had difficulty in eliminating excrement and exhibited a disorganization of the muscles fibers of the midgut, possibly due to the disarray of their myofibrils after the ingestion of insecticide chlorantraniliprole during the larval stage.

By means of ultrastructural analysis, we observed signs of cellular injury during the time period studied that included a reduction of myofilaments, swollen mitochondria and an accumulation of membranous structures near the sarcolemma. All of the evaluated concentrations induced cytotoxic effects, which were not concentration dependent. According to Scudeler et al. (2016b) the antifeedant and repellent effects could also explain this result, the low concentration of neem oil used in this experiment repelled fewer larvae from ingestion of the treated eggs, and therefore these larvae fed on large quantities of eggs and became more susceptible to the injurious effects of the neem. On the other hand, the high concentration of neem oil was strongly repellent to the larvae, but even the small amount of eggs consumed by this group resulted in damages. The malfunctioning of membranous structures that can lead to cellular vacuolation can be derived from the endoplasmic reticulum and mitochondria as a consequence of excessive cellular stress (Aki et al., 2012). Bernick et al. (2008) described this sign of degeneration that involved a deterioration of contractile elements in the midgut muscle during the larval-pupal transition in Aedes aegypti. Changes in mitochondria and membranes have been well documented in the midgut epithelium of $C$. claveri when exposed to neem oil (Scudeler and Santos, 2013, 2014; Scudeler et al., 2016a).

Although exposure to neem oil results in cytomorphological changes, cytochemical analysis showed that there was an increase in acid phosphatase activity in theses specimens; this enzyme plays a role in the detoxification process (Amirmohammadi et al., 2012; Valizadeh et al., 2013; Scudeler et al., 2016a). The increase in lytic activity is a mechanism for recovery after cell injury (Neerunjun and Dubowitz, 1977; Maltz and Oron, 1990; Cheville, 2009; Scudeler et al., 2016a). Acid phosphatase is a lysosomal enzyme, and during the cellular repair this lysosome activation acts to degrade cellular debris by autophagy. When the cell injury is significant, this lytic activity may not be able to process debris and therefore lead to accumulation of membranous structures derived of damaged organelles (Cheville, 2009). 
Despite the finding that muscle fibers exhibited evidence of this detoxification mechanism, cell damage such as a reduced number of contractile myofilaments, an accumulation of myelin structures, a dilatation of cisternae of the sarcoplasmic reticulum and mitochondrial swelling and cristolysis were present in the oviposition period. The presence of injuries and the damages present in the midgut epithelium compromise the function of this organ, as highlighted by Scudeler et al. (2016a), in studies on C. claveri that were exposed to neem oil. Cytotoxic changes in the endoplasmic reticulum and mitochondria are some of the earliest signs of injury caused by treatments with plant-derived and insecticides in most of the cells of insects (Lü et al., 2010; Ling and Zhang, 2011; Qi et al., 2011; Catae et al., 2014).

Alterations at this cellular level clearly indicate that the visceral muscle layer is also the target of action of neem oil, which accounts for the symptoms associated with the effects the azadirachtin on muscle tone and gut motility that have been described previously in the insects (Mordue (Luntz) et al., 1985; Mordue (Luntz) and Nisbet, 2000). These results indicate that neem oil intake by $C$. claveri is cytotoxic to muscle fibers of the midgut, which compromises the function of this organ. These muscle fibers demonstrated a recovery attempt, but we found that it was inadequate due to the high level of cellular damage. Finally, we emphasize that the analysis of muscle layers cannot be neglected in the evaluation of cytopathological effects on the midgut of the insect because it is a critical component for the function of this organ.

\section{Acknowledgements}

We are grateful to the Electron Microscopy Center of the Institute of Biosciences of Botucatu, UNESP. This work was supported by the São Paulo Research Foundation (FAPESP 2014/15016-2) and the Coordenação de Aperfeiçoamento de Pessoal de Nível Superior (CAPES).

\section{References}

Aggarwal, N., Brar, D.S., 2006. Effects of different neem preparations in comparison to synthetic insecticides on the whitefly parasitoid Encarsia sophia (Hymenoptera: aphelinidae) and the predator Chrysoperla carnea (Neuroptera: chrysopidae) on cotton under laboratory conditions. J. Pest Sci. 79, 201-207.

Aki, T., Nara, A., Uemura, K., 2012. Cytoplasmic vacuolization during exposure to drugs and others substances. Cell Biol. Toxicol. 28, 125-131.

Almeida, G.D., Zanuncio, J.C., Senthil-Nathan, S., Pratissoli, D., Polanczyk, R.A., Azevedo, D.O., Serrão, J.E., 2014. Cytotoxicity in the midgut and fat body of Anticarsia gemmatalis (Lepidoptera: geometridae) larvae exerted by neem seeds extracts. Invert. Surviv. J. 11, 79-86.

Amirmohammadi, F., Sendi, J.J., Zibaee, A., 2012. Toxicity and physiological effect of essential oil of Artemisia annua (Labiatae) on Agriolimax agrestis L. (Stylommatophora: limacidae). J. Plant Prot. Res. 52 (2), 185-189.

Bailey, A., Chandler, D., Grant, W.P., Greaves, J., Prince, G., Tatchell, M., 2010. Biopesticides: Pest Management and Regulation. CAB International, Cambrigde, http://dx.doi.org/10.1079/9781845935597.0000.

Bernick, E.P., Moffett, S.B., Moffett, D.F., 2007. Organization, ultrastructure, and development of midgut visceral muscle in larval Aedes aegypti. Tissue Cell 39, 277-292.

Bernick, E.P., Moffett, S.B., Moffett, D.F., 2008. Ultrastructure and morphology of midgut visceral muscle in early pupal Aedes aegypti mosquitoes. Tissue Cell 40 (2), 127-141.

Catae, A.F., Roat, T.C., Oliveira, R.A., Nocelli, R.C.F., Malaspina, O., 2014. Cytotoxic effects of thiamethoxan in the midgut and malpighian tubules of africanized Apis mellifera (Hymenoptera: apidae). Microsc. Res. Tech. 77, 274-281.

Chandler, D., Bailey, A.S., Tatchell, G.M., Davidson, G., Greaves, J., Grant, W.P., 2011. Phil. Trans. R. Soc. B 366, 1987-1998.

Cheville, N.F., 2009. Ultrastructural Pathology: The Comparative Cellular Basis of Disease, 2 ed. Willey-Blackwell, Ames.

Cloyd, R.A., 2012. Indirect effects of pesticides on natural enemies. In: Soundararajan, R.P. (Ed.), Pesticides-Advances in Chemical and Botanical Pesticides. Intech, Rijeka, Croatia, pp. 127-150.

Cordeiro, E.M.G., Corrêa, A.S., Venzon, M., Guedes, R.N.C., 2010. Insecticide survival and behavioral avoidance in the lacewings Chrysoperla externa and Ceraeochrysa cubana. Chemosphere 81, 1352-1357.

El-Wakeil, N., Gaafar, N., Sallam, A., Volkmar, C., 2013. Side effects of insecticides on natural enemies and possibility of their integration in plant protection strategies. In: Trdan, S. (Ed.), Insecticides - Development of Safer and More
Effective Technologies. Intech, Rijeka, Croatia. , pp. 3-56, http://dx.doi.org/10. $5772 / 54199$.

Gutiérrez, Y., Santos, H.P., Serrão, J.E., Oliveira, E.E., 2016. Deltamethrin-Mediated toxicity and cytomorphological changes in the midgut and nervous system of the mayfly Callibaetis radiatus. PLoS One 11 (3), e0152383, http://dx.doi.org/10. 1371/journal.pone.0152383.

Kux, K., Pitsouli, C., 2014. Tissue communication in regenerative inflammatory signaling: lessons from the fly gut. Front. Cell. Infect. Microbiol. 4, 1-7, http:// dx.doi.org/10.3389/fcimb.2014.00049.

Lü, M., Wu, W.J., Liu, H.X., 2010. Effects of fraxinellone on the midgut ultrastructural changes of Mythimna separata Walker. Pesticide Biochem. Phys. 98, 263-268.

Ling, S., Zhang, R., 2011. Effect of friponil on brain and muscle ultrastructure of Nilaparvata lugens (Stal) (Homoptera: delphacidae). Ecotoxicol. Environ. Saf. 74, 1348-1354

Malaspina, O., Silva-Zacarin, E.C.M., 2006. Cell markers for ecotoxicological studies in target organs of bees. Braz. J. Morphol. Sci. 23, 303-309.

Maltz, L., Oron, U., 1990. Proteolytic enzyme activities during regeneration of the rat gastrocnemius muscle. J. Neurol. Sci. 98, 149-154.

Medina, P., Smagghe, G., Budia, F., Tirry, L., Viñuela, E., 2003. Toxicity and absorption of azadirachtin, diflubenzuron, pyriproxyfen, and tebufenozide after topical application in predatory larvae of Chrysoperla carnea (Neuroptera: chrysopidae). Environ. Entomol. 32, 196-203.

Mordue (Luntz), A.J., Blackwell, A., 1993. Azadirachtin: an update. J. Insect Physiol. 39 (11), 903-924.

Mordue (Luntz), A.J., Nisbet, A.J., 2000. Azadirachtin from the Neem Tree Azadirachta indica: its action against insects. An. Soc. Entomol. Bras. 29, 615-632.

Mordue (Luntz), A.J., Cottee, P.K., Evans, K.A., 1985. Azadirachtin: its effect on gut motility, growth and moulting in Locusta. Physiol. Entomol. 10, 431-437.

Mordue (Luntz), A.J., Simmonds, M.S.J., Ley, S.V., Blaney, W.M., Mordue, W., Nasiruddin, M., Nisbet, A.J., 1998. Actions of Azadirachtin, a plant allelochemical, against insects. Pestic. Sci. 54, 277-284.

Morgan, E.D., 2009. Azadirachtin, a scientific gold mine. Bioorg. Med. Chem. 17, 4096-4105.

Munhoz, R.E.F., Bignotto, T.S., Pereira, N.C., Saez, C.R.N., Bespalhuk, R., Fassina, V.A. Pessini, G.M., Baggio, M.P.D., Ribeiro, L.F.C., Brancalhão, R.M.C., Mizuno, S., Aita, W.S., Fernandez, M.A., 2013. Evaluation of the toxic effect of insecticide chlorantraniliprole on the silkworm Bombyx mori (Lepidoptera: bombycidae). Open J. Anim. Sci. 3 (4), 343-353, http://dx.doi.org/10.4236/ojas.2013.34051.

Nasiruddin, M., Mordue (Luntz), A.J., 1993. The effect of azadirachtin on the midgut histology of the locusts Schistocerca gregaria and Locusta migratoria. Tissue Cell 25 (6), 875-884.

Neerunjun, J.S., Dubowitz, V., 1977. Concomitance of basophilia, ribonucleic acid and acid phosphatase activity in regenerating muscle fibres. J. Neurol. Sci. 33, 95-109.

Okwute, S.K., 2012. Plants as potential sources of pesticidal agents: a review. In: Soundararajan, R.P. (Ed.), Pesticides-Advances in Chemical and Botanical Pesticides. Intech, Rijeka, Croatia. , pp. 207-232, http://dx.doi.org/10.5772/ 46225.

Park, S.S., Shahabuddin, M., 2000. Structural organization of posterior midgut muscles in mosquitoes, Aedes aegypti and Anopholes gambie. J. Struct. Biol. 129, 30-37.

Pino, R.M., Pino, L.C., Bankston, P.W., 1981. The relationships between the Golgi apparatus, GERL, and lysosomes of fetal rat liver kupffer cells examined by ultrastructural phosphatase cytochemistry. J. Histochem. Cytochem. 29, $1061-1070$

Qi, Z.J., Shi, B.J., Hu, Z.N., Zhang, Y., Wu, W.J., 2011. Ultrastructural effects of Celangulin V on midgut cells of the oriental armyworm, Mythimna separata walker (Lepidoptera: noctuidae). Ecotoxicol. Environ. Saf. 74 (3), 439-444.

Ruiu, L., Satta, A., Floris, I., 2012. Observations on house fly larvae midgut ultrastructure after Brevibacillus laterosporus ingestion. J. Invert. Pathol. 111, 211-216.

Schaefer, C.W., Vanderberg, J.P., Rhodin, J., 1967. The fine structure of mosquito midgut muscle. J. Cell Biol. 34, 905-911.

Schmutterer, H., 1990. Properties and potential of natural pesticides from the neem tree, Azadirachta indica. Annu. Rev. Entomol. 35, 271-297.

Scudeler, E.L., Santos, D.C., 2013. Effects of neem oil (Azadirachta indica A. Juss) on midgut cells of predatory larvae Ceraeochrysa claveri (Navás, 1911) (Neuroptera: chrysopidae). Micron 44, 125-132.

Scudeler, E.L., Garcia, A.S.G., Padovani, C.R., Santos, D.C., 2013. Action of neem oil (Azadirachta indica A. Juss) on cocoon spinning in Ceraeochrysa claveri (Neuroptera: chrysopidae). Ecotoxicol. Environ. Saf. 97, 176-182.

Scudeler, E.L., Padovani, C.R., Santos, D.C., 2014. Effects of neem oil (Azadirachta indica A. Juss) on the replacement of the midgut epithelium in the lacewing Ceraeochrysa claveri during larval-pupal metamorphosis. Acta Histochem. 116, $771-780$.

Scudeler, E.L., Garcia, A.S.G., Padovani, C.R., Pinheiro, P.F.F., Santos, D.C., 2016a. Cytotoxic effects of neem oil in the midgut of the predator Ceraeochrysa claveri. Micron 80, 96-111.

Scudeler, E.L., Garcia, A.S.G., Padovani, C.R., Pinheiro, P.F.F., Santos, D.C., 2016b. Are the biopesticide neem oil and the predator Ceraeochrysa claveri (Navás, 1911) compatible? J. Entomol. Zool. Stud. 4 (2), 340-346.

Secundino, N.F.C., Nacif-Pimenta, R., Hajmova, M., Volf, P., Pimenta, P.F.P., 2005. Midgut muscle network in Lutzomyia longipalpis and Phlebotomus duboscqi 
sand flies: spatial organization and structural modification after blood meal. Arthropod Struct. Dev. 34, 167-178.

Valizadeh, B., Sendi, J.J., Zibaee, A., Oftadeh, M., 2013. Effect of neem based

insecticide Achook ${ }^{\Phi}$ on mortality, biological and biochemical parameters of elm leaf beetle Xanthogaleruca luteola (Col: chrysomelidae). J. Crop Prot. 2 (3), 319-330.
Xu, N., Wang, S.Q., Tan, D., Gao, Y., Lin, G., Xi, R., 2011. EGFR, Wingless and JAK/STAT signaling cooperatively maintain Drosophila intestinal stem cells. Dev. Biol. 354, 31-43. 